University of Otago

\title{
The impact of oil-market shocks on stock returns in major oil-exporting countries: A Markov-switching approach
}

\author{
Syed Abul Basher \\ Department of Economics, East West University, Plot No - A/2, Aftabnagar Main Road, \\ Dhaka 1219, Bangladesh \\ Email: syed.basher@gmail.com
}

Alfred A. Haug

Department of Economics, University of Otago, PO Box 56, Dunedin 9054, New Zealand Email: alfred.haug@otago.ac.nz

Perry Sadorsky

Schulich School of Business, York University, 4700 Keele Street, Toronto, Ontario, M3J 1P3, Canada Email: psadorsk@schulich.yorku.ca

Address for correspondence:

Alfred Haug

Department of Economics

University of Otago

PO Box 56

Dunedin

NEW ZEALAND

Email: alfred.haug@otago.ac.nz

Telephone: 6434795636 


\title{
The impact of oil-market shocks on stock returns in major oil-exporting countries: A Markov-switching approach
}

\author{
Syed Abul Basher \\ Department of Economics, East West University, Plot No - A/2, Aftabnagar Main Road, \\ Dhaka 1219, Bangladesh \\ Email: syed.basher@gmail.com \\ Alfred A. Haug \\ Department of Economics, University of Otago, PO Box 56, Dunedin 9054, New Zealand \\ Email: alfred.haug@otago.ac.nz \\ Perry Sadorsky \\ Schulich School of Business, York University, 4700 Keele Street, Toronto, Ontario, M3J 1P3, Canada \\ Email: psadorsk@ schulich.yorku.ca
}

September, 2017

\begin{abstract}
The impact that oil shocks have on stock prices in oil exporting countries has implications for both domestic and international investors. We derive the shocks driving oil prices from a fullyidentified structural model of the oil market. We study their nonlinear relationship with stock market returns in major oil-exporting countries in a multi-factor Markov-switching framework. Flow oil-demand shocks have a statistically significant impact on stock returns in Canada, Norway, Russia, Kuwait, Saudi Arabia, and the UAE. Idiosyncratic oil-market shocks affect stock returns in Norway, Russia, Kuwait, Saudi Arabia and UAE. Speculative oil shocks impact stock returns in Canada, Russia, Kuwait and the UAE. Flow oil-supply shocks matter for the UK, Kuwait, and UAE. Mexico is the only country where stock returns are unaffected by oil shocks. These results shed important light on investor sentiment toward the relationship between oil shocks and stock markets in oil exporting countries.
\end{abstract}

JEL Classification: E44, G15, Q43

Keywords: Markov-switching; oil-exporting countries; oil-market shocks; stock returns. 


\section{Introduction}

For many of the major oil-exporting countries, oil rents form a large share of GDP, with Kuwait in the upper range of 40-50\%, followed by Saudi Arabia, the United Arab Emirates, Russia, and Norway, with declining shares respectively, down to around 10\% (Figure 1). Hence, oil price shocks are likely important drivers of stock markets in oil-exporting countries that have reasonably well-functioning stock markets in terms of stock market capitalization relative to GDP (size of the stock market) and values of stock trades relative to GDP (liquidity of the stock market). ${ }^{1}$ Knowing the quantitative impact of oil price shocks in oil exporting countries is therefore of great relevance for portfolio construction and risk management of international investors in such global markets.

Kilian (2009) showed in a seminal paper that the reasons of oil price changes matter crucially for their effects on real GDP in the US, an oil importing country. Kilian and Park (2009, p. 1267) pointed out that studies that ignore the source of oil price shocks are biased towards finding no statistically significant relationships between oil price shocks and variables such as stock prices. There are two reasons for that. First, oil-supply and oil-demand shocks have normally different effects on economic and financial markets. Second, the relationship between oil price shocks and macroeconomic and financial variables likely changed over time, with oil price shocks having less of an effect on real GDP in recent decades in oil importing countries.

The structural oil-market model of Kilian (2009), used in numerous empirical studies, was generalized by Kilian and Murphy (2014) in order to capture unobservable shifts in expectation about future oil demand and supply. They explained how, through arbitrage, crude oil inventories above ground reflect such changes in expectations. Therefore, they introduced above-ground crude oil-inventory changes in the oil-market model of Kilian (2009) as an additional variable, capturing the speculative demand for crude oil. This approach makes it feasible to explicitly identify structural speculative oildemand shocks for crude oil and to evaluate their role for stock market returns. Furthermore, the second

\footnotetext{
${ }^{1}$ See Baumeister and Kilian (2016) for a detailed analysis of oil price fluctuations over the past forty years. Large price fluctuations have been a recurring feature in oil markets and recent years are no exception.
} 
generation oil-market model of Kilian and Murphy (2014) does not impose zero short-run (on impact) price elasticities for oil supply and oil demand, as was the case in the framework of Kilian (2009). Baumeister and Hamilton (2015), among others, recently criticized this aspect of Kilian's (2009) modelling framework.

The Markov switching model (Hamilton, 1990) is a flexible framework for studying the relationship between oil shocks and stock markets. It allows for time-varying causality across regimes, whereas linear models assume constant parameters and no regime (structural) changes. In the estimation of Markov models all information about the varying regime-switching probabilities of being in a particular regime is used, i.e., the full sample is used. Breaks are not imposed or treated as one-time events with zero probability of recurring. Instead, the Markov framework lets the data determine the probabilities of change, and changes are assumed to reoccur with non-zero probability. This is in sharp contrast to standard tests for structural breaks that treat a break or multiple breaks as unique events (at known or unknown points in tine), with a zero probability of occurring again in the future and hence being ignored in forecasting (Hamilton, 2016).

We follow Kilian's (2009) two-stage approach. However, we derive the structural shocks from the fully identified oil-market model of Kilian and Murphy (2014). We first estimate a structural vectorautoregressive (VAR) model and identify, with sign restrictions and elasticity bounds, four structural oil shocks: a flow oil-supply shock, a flow oil-demand shock, a speculative oil-demand shock, and an oilmarket-specific idiosyncratic oil price shock not captured by the previous three shocks. In the second stage, we assess the impact of each of these shocks on excess stock returns within a Markov-switching framework. The Markov model that we apply allows for volatility to differ across regimes so that the model can capture the time-varying volatility in stock markets, which is a significant stylized fact in financial markets. In addition, we explore what global factors affect the state probability of market transition between low and high volatility regimes, using a "probit" model.

Our paper contributes to the literature in three ways: (i) we combine the fully identified structural VAR oil-market model of Kilian and Murphy (2014) with a Markov switching model for stock returns, 
using a two-stage analysis; (ii) we study the impact of speculative behavior in the crude oil market on stock market returns, after accounting for the roles of flow oil-supply shocks and flow oil-demand shocks, and (iii) we do this for major oil exporting countries that have seen an increased interest in their stock markets from international investors in recent years. Overall, we find that at least one of the four structural shock has a statistically significant effects on excess stock returns in one of the Markov states, except for Mexico that is unaffected by oil-market shocks. The domestic excess stock returns respond statistically significantly to all four shocks in Kuwait and the United Arab Emirates, to flow oil-demand, idiosyncratic and speculative (inventory) shocks in Russia, to flow oil-demand and idiosyncratic shocks in Norway and Saudi Arabia, to flow oil-demand and speculative shocks in Canada, and to flow oilsupply shocks only in the UK.

The paper is organized as follows. Section 2 presents a brief discussion of theoretical transmission channels between oil prices and stock prices. An overview of the related literature is also included. Section 3 discusses the econometric approach in some detail, and Section 4 describes the data. Section 5 offers the empirical results and Section 6 concludes the paper.

\section{Oil price shocks and the role of stock markets in oil-exporting countries}

Theoretically, oil prices can affect stock prices in oil-exporting countries in several ways. At any time, the price of a share in a company is equal to the expected present value of discounted future cash flows (Huang et al., 1996). Oil price shocks can affect stock prices directly by affecting current and future cash flows or indirectly by affecting interest rates that are used to discount the future cash flows. Unless there is complete substitution between factors of production, rising oil prices generally increase the cost of doing business when oil is used as an input. Oil is an essential input in the production of many goods and services. For non-oil related companies, a positive unexpected increase in oil prices will usually reduce cash flows and stock prices and hence lead to a reduction of realized stock returns. For oil related companies, involved in the production of oil, this generally increases cash flows and stock prices, along with realized stock returns. The effects depend on how inelastic the demand for oil is and on the time 
horizon considered (i.e., short- versus longer-run elasticities). The increase in stock prices and stock returns for oil related companies will increase consumption and investment through the wealth and income channels and with it economic activity and real GDP. The opposite effects occur for non-oil related companies. Furthermore, oil royalties for governments in oil-producing countries may increase as well when oil prices go up, depending on elasticities of oil demand and on how royalties are levied. Such royalties may be used for additional domestic government spending, say to increase transfer payments to households or to build up the domestic infrastructure, and thus lead to further economic stimulus.

The effects of oil price shocks in the stock-pricing formula depend also on the interest rate used for discounting the expected future cash flows. The nominal interest rate in turn depends on expected inflation and expected real rates of interest. These depend on aggregate demand and supply conditions in an economy, which are influenced by monetary and fiscal policies and by trade effects as well. An economic slow-down in oil-importing countries will affect non-oil related exports originating in oilexporting countries. Depending on the size of the non-oil export sector in oil-exporting countries, oilexporting countries will see a negative stimulus coming through the trade channel. The net effect for oilexporting countries may be positive or negative. ${ }^{2}$ Bjørnland (2009) pointed out that Norway, a net oil exporter, has benefited from oil price increases, showing temporary increases in economic growth, whereas Canada, also a net-oil exporter, has shown instead declines in economic growth, more in line with the effects of oil price hikes in oil-importing countries.

Numerous studies have analyzed the impact of oil price shocks on stock markets, as for example Ferson and Harvey (1994), Jones and Kaul (1996), Sadorsky (1999; 2001), Hammoudeh and Aleisa (2004), El-Sharif et al. (2005), Basher and Sadorsky (2006), Boyer and Filion (2007), Park and Ratti (2008), Kilian and Park (2009), and Basher et al. (2012). The literature has mostly focused on the US and other oil-importing developed countries and less on emerging markets, developing countries, and oilexporting countries.

\footnotetext{
${ }^{2}$ For the oil-exporting countries, a positive terms of trade shock may also eventually lead to a Dutch Disease phenomenon. This is caused by an increase of the price of the non-tradable goods and an appreciation of the real exchange rate (Buetzer et al., 2016).
} 
The literature on oil shocks and stock markets in oil-exporting countries is relatively sparse. Some studies on emerging economies included a few of the oil exporters as part of the emerging economies but generally did not analyze them separately (e.g., Basher and Sadorsky, 2006) or looked at a composite emerging markets index instead (Basher et al., 2012). Only a few papers directly consider oil-exporting countries. For example, Sadorsky (2001) explored the relationship between oil prices and equity values in the Canadian oil and gas sector. He found a significant positive relationship between the oil equity index and the price of crude oil, with a $1 \%$ increase in oil prices being associated with a $0.305 \%$ increase in the value of the index. Mohanty et al. (2011) found that, except for Kuwait, oil price changes are associated with increased stock price returns in the GCC countries. In examining dynamic correlation between oil prices and stock prices Filis et al. (2011) found that dynamic correlation does not differ between oil-importing countries and oil-exporting countries. Guesmi and Fattoum (2014) find similar evidence using a slightly different selection of oil-importing and oil-exporting countries. There is also some evidence that oil prices have asymmetric impacts on stock returns. Ramos and Veiga (2013) found that the impact of oil price changes on stock prices depends upon whether a country is a net oil importer or net oil exporter. In particular, oil price increases have a positive impact on stock markets in oil exporting countries. Also, Demirer et al. (2015) found that, for Gulf Arab stock markets, higher oil prices lead to higher stock returns.

In contrast to the above studies, Kilian and Park (2009) used the oil-market model of Kilian (2009) and documented that the effect of oil price shocks on the US stock market differs significantly, depending on the source of the oil price change. They found that positive oil-demand shocks depressed US stock prices, while oil-supply shocks had little impact on stock prices. Sim and Zhou (2015) used as well the two-stage model in Kilian (2009) to study the effect of the quantiles of the oil-specific shocks on the quantiles of the US stock returns and found asymmetric effects. Further, Aspergis and Miller (2009) used the two-stage Kilian (2009) framework in order to investigate the impact of oil shocks on the stock markets of Australia, Canada, France, Germany, Italy, Japan, and the United States. They found that the impact of oil shocks on stock prices is small. On the other hand, Jung and Park (2011) compared the 
relationship between stocks and oil prices in Norway and South Korea, using the SVAR in Kilian and Park (2009). They found that the responses of stock returns and volatility differ substantially, depending on the cause of the oil price change and on whether a country is a net oil exporter or importer. Kang and Ratti (2013) add a variable for economic policy uncertainty to the Kilian and Park (2009) model and find that structural oil shocks account for approximately $32 \%$ of the long-term variability in stock returns while economic policy uncertainty accounts for 19\%. Furthermore, Wang et al. (2013) extended the linear SVAR approach of Kilian and Park (2009) to various oil-exporting and oil-importing countries. They found that the effects of oil price shocks on local stock markets differ by magnitude, duration, and direction according to whether a country is a net oil-exporter or net oil-importer and according to the type of oil shock. Kang et al. (2015) combine the Kilian and Park (2009) SVAR model with a time-varying parameter VAR and find evidence of time variation in the estimated coefficients and the variancecovariance matrix. The contribution of each oil shock has changed across time.

A few studies applied the Markov-switching model to analyze the relationship between oil price shocks and financial markets. Chen (2010) used a Markov-switching model to study the impact of oil price shocks on US stock returns. He found evidence that an increase in oil prices increased the probability of a bear market. The results are robust to different measures of oil prices changes and several different measures of broad-based US stock markets. Beckmann and Czudaj (2013) applied the Markovswitching model to the relationship between oil prices and exchange rates. Beckmann and Czudaj (2013) considered five major oil-exporting and six oil-importing countries, as well as the euro area. Their shortrun nonlinear vector error-correction follows a two-state Markov-switching regime that is embedded within a long-run linear cointegrating relationship (with no Markov-switching). Also, Balcilar et al. (2015) used a Markov-switching vector error-correction model with two variables, namely historic US oil prices and stock prices. However, these authors did not study the sources of oil price shocks when analyzing the Markov-switching dynamics, because their econometric framework is not quite suitable for this purpose. On the other hand, Basher et al. (2016) used a different Markov model and considered the sources of oil shocks as in Kilian (2009) in the analysis of the dynamics between oil price shocks and 
exchange rates. The above results generally supported the presence of regime switching for the effects of oil shocks. Moreover, Angelidis et al. (2015) used a Markov-switching model in a two-stage Kilian (2009) setting to analyze the impact of oil shocks on Dow Jones stock returns and volatility, and found that oil demand and supply shocks help explain the transition from low volatility to high volatility states.

A further crucial aspect in the relationship between oil prices and macroeconomic or financial variables is whether oil price increases have different effects from oil price decreases, i.e., whether there is asymmetry. Mork (1989) argued for asymmetric effects of oil price changes. He found that increases in the real price of oil have much more predictive power for US real output growth than declines. Moreover, Hamilton (2003) defined a net oil price increase as the relevant variable to model the effects of oil prices on the economy. His oil price measure included only oil price increases that represent new highs relative to the recent experience, or reversals of recent decreases. Various definitions of this net oil price increase have been used with varying lag lengths in order to determine new highs of the oil price. However, Kilian and Vigfusson (2011) discussed econometric issues in regards to oil price shocks and presented empirical evidence in favor of effects on output being linear and symmetric. ${ }^{3}$ Our Markovswitching model has the advantage that it determines relevant regimes that prevail over time from the data without imposing a strict formula for switches, as Hamilton's net oil price does by using specific time periods when oil prices reach new highs.

\section{Empirical methodology}

We employ the two-stage approach developed by Kilian (2009). However, we use the oil-market SVAR model of Kilian and Murphy (2014) with four variables instead of the model of Kilian (2009) with three variables only to model the oil market. We construct in the first stage the four structural shocks in the crude oil market. In order to identify structural shocks we use sign restrictions and elasticity bounds, following Kilian and Murphy (2014). In the second stage, we empirically assess the responses of stock

\footnotetext{
${ }^{3}$ See the reply by Hamilton (2011).
} 
market returns of selected major oil-exporting countries to the four oil shocks identified, using a Markovswitching framework (Hamilton, 1990).

The modelling framework of Kilian (2009) explicitly identified global crude oil-supply shocks due to changes in world oil production and global aggregate demand shocks due to changes in the world demand for oil resulting from business cycle fluctuations. A third oil-market-specific shock was only implicitly identified in Kilian (2009). This third structural shock was designed to capture all other shocks besides oil-supply and oil-demand shocks that hit the oil market and thus the third structural shock forms a residual shock category, which complicates the economic interpretation of these residual shocks. In contrast, the second generation oil-market SVAR of Kilian and Murphy (2014) explicitly identifies speculative oil-demand shocks in addition to flow oil-supply shocks and flow oil-demand shocks. Kilian and Murphy's (2014) SVAR represents a fully specified structural model of the oil market. The residual shocks in this model capture shocks to real oil prices such as extreme weather events, changes in storage technology or preferences, etc. Crude oil inventories above the ground reflect speculative motives in regards to future oil price movements or the degree of concerns about future oil supplies, including precautionary motives and strategic oil reserves. Usual arbitrage arguments link the demand for physical oil inventories with financial futures markets for crude oil (Kilian and Murphy, 2014). On the other hand, speculative behavior of oil producers, such as pumping less crude oil from below-ground in anticipation of higher future oil prices, is captured by the flow oil-supply variable in the SVAR model.

\subsection{Identification of global oil shocks and estimation of the SVAR model}

Oil demand and supply, both in flow terms, are cast in an SVAR model specified as:

$$
A_{0} y_{t}=A(L) y_{t-1}+\varepsilon_{t}
$$

where $y_{t}$ is a vector with four variables for $t=1, \ldots, n$ : (i) the percentage change in global oil production (prod), (ii) an index of global economic activity (rea), (iii) the natural logarithm of the real price of oil (in US dollars; rpo), and (iv) global oil-inventory changes (inv); $\varepsilon_{t}$ is a vector of serially and mutually 
uncorrelated structural innovations that have economic meaning. The reduced-form VAR, where $e_{t}=$ $A_{0}^{-1} \varepsilon_{t}$ is a vector of correlated errors, is estimated from:

$$
y_{t}=A_{0}^{-1} A(L) y_{t-1}+e_{t}
$$

The orthogonal structural innovations are derived from the reduced form estimates in equation (2) by imposing various restrictions on $A_{0}^{-1}$. We model the crude oil market as in Kilian and Murphy (2014). The four structural shocks in equation (1) are interpreted as follows: $\varepsilon_{1 t}^{S}$ represents shocks to the global supply of crude oil above the ground (flow supply) that we label "supply shock"; $\varepsilon_{2 t}^{d}$ captures shocks to flow oil demand due to changes in the global demand for all industrial commodities that reflect changes in global real economic activity caused by business cycle fluctuations ("demand shock"); $\varepsilon_{3 t}^{i d i}$ represents all other (residual) oil-market specific idiosyncratic demand shocks ("idiosyncratic shock"); and $\varepsilon_{4 t}^{i n v}$ is a shock to above-ground oil inventories due to speculative concerns over future oil demand and supply ("inventory shock"). The identification of $A_{0}^{-1}$ is achieved by imposing restrictions:

$$
e_{t}=\left(\begin{array}{c}
e_{1 t}^{\text {prod }} \\
e_{2 t}^{r e a} \\
e_{3 t}^{r p o} \\
e_{4 t}^{i n v}
\end{array}\right)=\left[\begin{array}{cccc}
- & + & + & \text { none } \\
- & + & - & \text { none } \\
+ & + & + & \text { none } \\
\text { none none } & + & \text { none }
\end{array}\right]\left(\begin{array}{c}
\varepsilon_{1 t}^{s} \\
\varepsilon_{2 t}^{d} \\
\varepsilon_{3 t}^{i d i} \\
\varepsilon_{4 t}^{i n v}
\end{array}\right) .
$$

Following Kilian and Murphy (2014), all structural shocks have been normalized to imply an increase in the real price of oil. Their methodology involves sign restrictions and restrictions on the bounds of the price elasticity of oil supply and the price elasticity of oil demand for the impact responses in equation (3). Kilian and Murphy (2012) illustrated that sign restrictions on the impact of responses alone, as shown in equation (3), are generally too weak to be informative for identification of the shocks. Kilian and Murphy (2014) therefore imposed further restrictions, following the methodology developed by Inoue and Kilian (2013). ${ }^{4}$ The dynamic response of the real price of oil to a negative oil-supply shock must have an initial positive impact on the real price of oil for at least 12 months. They also imposed restrictions on the short-run price elasticities of oil supply and of oil demand. The bounds imposed are [0,

\footnotetext{
${ }^{4}$ In contrast to the conventional approach to sign-identified VARs, Inoue and Kilian's (2013) method avoids problems associated with impulse responses that lack a specific corresponding structural model.
} 
0.025] for the price elasticity of oil supply on impact. The oil demand elasticity in production, which is usually used in the literature, sets the production of oil equal to the consumption of oil. When oil inventory changes play a role, this definition cannot be used. Following Kilian and Murphy (2014), we use instead the price elasticity for oil demand "in use" that excludes inventory changes, because inventory oil is not in use but in storage. The elasticity of oil demand in use is weakly negative on impact, in addition to having a lower bound determined by a long-run elasticity of -0.8 , so that we impose for identification $-0.8 \leq$ "price elasticity of oil demand in use" $\leq 0$ for the effect on impact. ${ }^{5}$

Bayesian methods are used for the estimation of the SVAR model and the associated impulse response functions. These methods allow assigning a posterior density value to each admissible structural model that satisfies the identifying restrictions outlined above. A standard Gaussian-inverse Wishart prior distribution for the reduced-form VAR parameters and a Haar distribution for the rotation matrix are assumed. The posterior distribution of the structural impulse responses is derived by applying the identification criteria to each draw of the parameters and rotation matrix (used in constructing the structural impact multiplier matrix for the impulse responses) from those prior distributions. We will repeat this procedure for five million draws and discard structural models that imply impulse responses not obeying the identifying restrictions.

We include seasonal dummies in the VAR in order to account for seasonal effects. Furthermore, we do not impose unit roots and cointegration on the estimated VAR in equation (2), i.e., we do not apply a vector error-correction model. Sims et al. (1990) showed that consistent parameter estimates can be obtained by applying least squares to VARs, despite the presence of variables with unit roots, as long as the variables with unit roots are cointegrated among themselves. In other words, it is not necessary to impose cointegration to achieve consistency of the estimates. Also, Hamilton (1994, pp. 651-653) provided some detailed discussion on this approach and pointed to pitfalls of imposing invalid cointegration restrictions. Moreover, it is incorrect to use first-differences of variables (that have unit

\footnotetext{
${ }^{5}$ Kilian and Murphy (2014) experimented with alternative elasticities of oil supply for an upper bound as large as 0.1 and found qualitatively similar results for impulse responses. See also Baumeister and Hamilton (2015) on the critical role of the short-run price elasticities.
} 
roots) in a VAR when cointegration is present because then missing error-correction terms create omitted variables problems. For our data, standard Phillips-Perron and DF-GLS test results (available from the authors on request) showed strong evidence in favor of unit roots for the global real economic activity variable and for the log of the real oil price. Cointegration is supported by usual Engel-Granger tests between these two variables. On the other hand, the percentage change in the oil supply and the change in crude oil inventories are variables that are covariance stationary. ${ }^{6}$ Hence, the above VAR specification is consistent with the requirements of Sims et al. (1990). In addition, we tested each of the four oil shock series, described in (3), for unit roots and found that these are well described as covariance stationary processes. Therefore, cointegration modelling is not needed.

\subsection{Markov-switching}

The next step in our analysis is to specify a Markov-switching model in order to study what effects the four oil shocks have on stock market returns in each of the oil exporting countries. The structural oilmarket shocks have been constructed from the reduced-form VAR residuals by imposing sign and elasticity bounds restrictions in such a way that they are orthogonal (Kilian and Murphy, 2014, p. 463). The extent to which these shocks are orthogonal to excess stock returns depends in part on how well the VAR is specified. The oil-supply, oil-demand, and speculative shocks are each explicitly identified, whereas the idiosyncratic shocks are only implicitly identified because they capture all other residual influences. However, the second stage regression estimates are consistent as long as the shocks are at least predetermined variables with respect to unexpected changes in stock returns so that there is no feedback from excess stock returns to the shocks within the month. It is commonly assumed that oil-market shocks are predetermined with respect to other macroeconomic and financial variables; see for example Kilian (2009), among others. In particular, we follow Kilian and Park (2009) and treat oil prices as predetermined with respect to stock market returns. This means that excess stock market returns are

\footnotetext{
${ }^{6}$ The inclusion of the oil demand elasticity in the model requires that oil inventories are specified in changes rather than percent changes. See Kilian and Murphy (2014).
} 
allowed to respond contemporaneously to oil supply, demand, speculative and idiosyncratic shocks. On the other hand, shocks to excess stock returns in oil-exporting countries do not affect global oil production, global real economic activity, global speculative oil demand, and global real oil prices within the month but may have effects with a delay of a month or more.

The oil-market shocks are generated regressors in the second stage regressions. Usually, generated regressors do not cause problems for coefficient estimates in second stage regressions but the estimates of the standard errors of the coefficients are not consistent because the sampling variation in the generated regressors is ignored (e.g., Wooldrigde, 2010). However, these implications depend on the exact model specification and assumptions. Our setup fits Model 4 in Pagan (1984, p. 232) with $\gamma=0$. He (p. 233) showed that in this case $(\gamma=0)$ the second stage ordinary least squares estimators are efficient and produce consistent estimates of coefficients and standard errors, and estimation and inference can proceed as usual. Murphy and Topel (1985) extended these results to models that are nonlinear. Hence, all our estimates in the second stage are unaffected by generated regressor problems as we do not include lags on the shocks.

We proceed by specifying a multi-factor model to relate stock returns to oil shocks. This approach has been widely used to study the impact of oil prices on stock returns (e.g. Sadorsky, 2001; Boyer and Filion, 2007; Basher and Sadorsky, 2006). A linear multi-factor model for stock market returns has the following form:

$$
s r_{i, t}=\beta_{0, i}+\beta_{1, i} \varepsilon_{i, t}^{s}+\beta_{2, i} \varepsilon_{i, t}^{d}+\beta_{3, i} \varepsilon_{i, t}^{i n v}+\beta_{4, i} \varepsilon_{i, t}^{i d i}+\beta_{5, i} \text { world }_{t}+u_{i, t},
$$

where $s r_{i . t}$ is excess stock market returns in country $i$, expressed in percentages. The oil shock variables are from the SVAR in the previous section: an oil-supply shock $\left(\varepsilon^{s}\right)$, an oil-demand shock $\left(\varepsilon^{d}\right)$, an oilinventory shock $\left(\varepsilon^{i n v}\right)$, and any other idiosyncratic shocks to oil demand $\left(\varepsilon^{i d i}\right)$. We also include the excess return of the world stock market index $\left(\right.$ world $\left._{t}\right)$ to control for other influences on returns of stocks in oilexporting countries, besides the oil shocks. 
We specify now the multi-factor Markov switching model in order to account for the possible nonlinear relationship between stock returns and oil shocks.

$$
s r_{i, t}=\beta_{0, i, s_{t}}+\beta_{1, i, S_{t}} \varepsilon_{i, t}^{S}+\beta_{2, i, S_{t}} \varepsilon_{i, t}^{d}+\beta_{3, i, S_{t}} \varepsilon_{i, t}^{i n v}+\beta_{4, i, s_{t}} \varepsilon_{i, t}^{i d i}+\beta_{5, i, s_{t}} \text { world }_{i, t}+u_{i, t}
$$

The Markov specification allows the impact of oil shocks on stock returns to be state $\left(s_{t}\right)$ dependent. The probability of transition from the State 1 in period $t$ to the State $m$ in period $t+1$ depends upon the state in period t only. Within each regime, the Markov process is conditionally linear. Switching between regimes is stochastic, which is driven by a time-varying transition probability matrix. In our model, the transition probability matrix changes depending on the values of the intercept, the variance, the four oil shocks and the world stock market variable. It is commonly assumed that the stochastic regime generating process follows an ergodic, homogeneous, first-order Markov chain. The number of regimes $(M)$ is finite and transition probabilities are constant:

$$
p_{l m}=\operatorname{Pr}\left(s_{t+1}=m \mid s_{t}=l\right), \quad p_{l m} \geq 0, \quad \sum_{m=1}^{M} p_{l m}=1, \quad \forall l, m \in\{1, \ldots, M\} .
$$

The Markov-switching models were estimated with two states, state dependent regression coefficients, and state dependent volatility for the error process, because stock market returns are known to exhibit volatility clustering.

A good fitting Markov-switching model provides a classification of regimes with estimated (smoothed) probabilities that are either close to one or zero. We use the regime classification measure, RCM, of Ang and Bekaert (2002). It allows us to determine the accuracy of the various estimated Markov-switching models. It is computed as follows:

$$
R C M(S)=100 S^{2} \frac{1}{T} \sum_{t=1}^{T} \prod_{j=1}^{S} \tilde{p}_{j, t}
$$

The average of the product of smoothed probabilities is denoted by $\tilde{p}$ and $\mathrm{S}$ is the number of regimes or states, S. The switching follows a Bernoulli distribution and hence the RCM provides an estimate of the variance. The statistic ranges from perfect regime classification with a value of 0 to a failure to detect any regime classification with a value of 100 . Therefore, lower values of the RCM are preferable to higher 
values of the RCM in regards to the overall fit of the Markov-switching model, along with its smoothed probability indicator close to 1 .

\section{Data}

We used monthly data on world oil supply, global real economic activity, global crude oil inventories, oil prices, and stock market indices. The start date is January 1974 and the end date is August 2015, the latest date for which all variables were available when this research project was started. The world oil supply, in millions of barrels per day, is taken from the US Energy Information Administration's (EIA) web site. ${ }^{7}$ An index of global real economic activity is sourced from Lutz Kilian's website. ${ }^{8}$ Global crude oil inventories refer to oil inventories above the ground and these are approximate by OECD crude oil inventories. ${ }^{9}$ We updated the data available from Kilian and Murphy (2014) beyond August 2008, with data from the EIA and data adjustments kindly supplied to us by Lutz Kilian. OECD data is only available for petroleum inventories and not for crude oil inventories. Following Kilian and Murphy (2014), US crude oil inventories are scaled with the ratio of OECD petroleum stock to US petroleum stocks in order to arrive at OECD crude oil inventories. Further data construction details are given in Kilian and Murphy (2014). ${ }^{10}$ Nominal oil prices in US dollars per barrel are measured by US refiner acquisition cost of imported crude oil. ${ }^{11}$ Real oil prices are calculated with the US CPI. ${ }^{12}$

Data on stock market indices for individual countries as well as for the World Stock Market are collected from MSCI. ${ }^{13}$ For each country, monthly returns on stock market indices are calculated as $\log$

\footnotetext{
${ }^{7}$ https://www.eia.gov/totalenergy/data/monthly/

${ }^{8}$ http://www-personal.umich.edu/ lkilian/paperlinks.html

9 Kilian and Murphy (2014) note that (below-ground) oil reserves are not included as they are not necessary for identification of the SVAR model. Also, below-ground oil reserves are not accessible in the short run as additional infrastructure needs to be put in place first. Aside from that, there are no reliable data on below-ground oil stocks. ${ }^{10}$ On the accuracy of this definition of inventories, see Kilian and Lee (2014). They (p. 85) showed that an alternative measure of inventories derived from proprietary data leads to "very similar results in general," despite having larger amplitude and the correlation between the two inventory measures being relatively low.

${ }^{11}$ https://www.eia.gov/petroleum/data.cfm\#prices

${ }^{12}$ https://fred.stlouisfed.org/search?st=us+cpi

13 The indexes are explained at https://www.msci.com/indexes.
} 
differences. These data are all in US dollars. The three-month US T-bill is used as a proxy for the risk free asset used to calculate excess stock market returns.

Consistent with previous studies, our choice of countries is determined by data availability of major oil-exporting countries. Furthermore, we choose among the top fifteen crude oil exporting countries, as ranked by the US Central intelligence Agency's "The World Factbook", those countries with relatively well-functioning stock markets. ${ }^{14}$ The ranking, retrieved on 11 November 2016, is based on the total amount of crude oil exported in a given year, with data availability ranging from 2012 to 2014 depending on the country. The top fifteen crude-oil exporters are (listed from highest to lowest): Saudi Arabia, Russia, Canada, United Arab Emirates (UAE), Nigeria, Iraq, Kuwait, Angola, Kazakhstan, Venezuela, Iran, Qatar, Mexico, Norway, and Algeria. In order to assess how well the stock market is functioning, we employ data on market capitalization and stock values traded. Market capitalization is defined as the share price times the number of shares outstanding for listed companies, as a percentage of GDP. Stock values traded are also specified as a percentage of GDP. Data, mostly for 2013 to make it comparable to the CIA data, are taken from the World Bank's World Development Indicators database, as of 17 November 2016. ${ }^{15}$

No data are available for Iraq, Angola, and Algeria, so that we exclude these countries from our analysis. We exclude also Nigeria, Kazakhstan, and Venezuela because of low market capitalization and stock values traded (relative to the other countries), which are below $16 \%$ and $1.3 \%$, respectively. We exclude Iran due to the embargo imposed on its oil exports during our sample period, and Qatar due to its overall small size of the stock market. All other countries show market capitalizations above $34 \%$ and trade values above 10\%, except for the UAE (with $5.5 \%$ in 2013 but with higher numbers in most other years). Additionally, we include the UK as a control. It is ranked by the CIA on place nineteen and has

\footnotetext{
${ }^{14} \mathrm{https} / / / \mathrm{www}$. cia.gov/library/publications/the-world-factbook/rankorder/2242rank.html

${ }^{15} \mathrm{http} / / /$ data.worldbank.org/indicator/CM.MKT.LCAP.GD.ZS;

http://data.worldbank.org/indicator/CM.MKT.TRAD.GD.ZS
} 
been an oil exporter for most of our sample period. ${ }^{16}$ Our chosen set of major oil exporting countries therefore is: Canada, Mexico, Norway, Russia, the UK, Kuwait, Saudi Arabia, and the UAE, ordered alphabetically by geographical region (North America, Europe, and the Middle East).

We will study the effect of uncertainty on the probability of transitioning between low and high volatility states. For this purpose, we use the filtered Markov-switching probability associated with each country's low volatility state as the dependent variable and regress it on a global factor: a global interest rate as a proxy for global uncertainty and, alternatively, a global economic policy uncertainty index, available online. The first measure is calculated as the difference in the yield spread between the threemonth Eurodollar LIBOR (London Interbank Offered Rate) and the three-month US Treasury bill rate. It is the so-called "TED spread." Fluctuations in the TED spread may capture fluctuations in global credit risks (Ferson and Harvey, 1994). ${ }^{17}$ The second measure is the global economic policy uncertainty (EPU) index of Baker et al. (2016), calculated as the GDP-weighted average of monthly EPU index values for the US, Canada, Brazil, UK, Ireland, Germany, Spain, France, Netherlands, Italy, Russia, India, China, South Korea, Japan, and Australia. The national EPU indices include measures of uncertainty such as the frequency of keyword searches for terms like "uncertainty", "economic crisis", or "budget deficit" in newspapers. ${ }^{18}$

Figure 2 plots stock price indexes of the eight markets considered in this study. A cursory look at this figure shows a remarkably similar pattern for the impact of the global financial crisis in 2008. Except for Canada and Mexico, the stock markets in the other the six countries stayed in the post-crisis period well below their pre-crisis peak in early 2008. For Saudi Arabia and the UAE, an even bigger market crash occurred in early 2006, when share prices collapsed by $75 \%$ and 57\%, respectively (Basher et al., 2014). Share prices in these two largest Middle Eastern markets have not returned yet to their pre-2006 level.

\footnotetext{
16 The UK became a net oil importer in 2005. For crude oil and natural gas liquids it is a net importer since 2013. See https://www.eia.gov/todayinenergy/detail.cfm?id=16971.

${ }^{17}$ Interest rates are available from the Federal Reserve Bank of St. Louis at http://research.stlouisfed.org/fred2/.

18 The monthly global index is available at http://www.policyuncertainty.com from January 1997.
} 


\section{Empirical results}

5.1 Global structural oil-market shocks and their effects on oil-exporters' excess stock returns

We implement the SVAR identification and estimation procedures outlined in Section 3.1. Our sample period, from February 1974 to August 2015, produces 103 admissible structural VAR models that satisfy the identifying assumptions. This compares to only 16 admissible structural models in Kilian and Murphy's (2014) sample that ended in August 2008. We estimated a value of -0.2539 for the posterior median of the price elasticity of oil demand in use. We follow Kilian and Murphy (2014) and choose among the admissible SVAR models the one that has an elasticity of oil demand in use closest to this value. Table 1 presents selected summary statistics of the variables used in the empirical model. The first four variables are the orthogonal shocks from this SVAR. As constructed, the normalized oil shocks have zero mean and the same standard deviation. The remaining variables in Table 1 are the monthly excess returns of stock markets including the world stock market. Not surprisingly, the average monthly returns of the three Middle Eastern markets are negative, partly because the available samples for these markets coincide with two large stock market crashes in 2006 and 2008, and partly due to the limited absorptive capacity of these economies beyond the oil sector (Basher and Fachin, 2013). The standard deviations of stock returns always exceed their mean levels, implying extremely high volatility of returns in national and world stock markets. However, among the eight stock markets, the extremely high volatility of Russia and the UAE is particularly noteworthy, providing a heuristic impression that these markets are prone to speculative attacks. The last two columns in Table 1 present the Phillips-Perron and DF-GLS unit root test statistics. The Phillips-Perron tests are highly statistically significant for each of the countries, implying that the null hypothesis of a unit root in stock returns for these countries is rejected at conventional significance levels.

We present next the results of the BDS (Brock et al. 1987 and Brock et al. 1996) test, which is commonly used to test for the presence of nonlinearity in the data. The null hypothesis of the BDS test is that increments to stock returns are independent and identically distributed, or equivalently, are iid. For the test, a distance $\varepsilon$ is chosen. The probability of the distance between a pair of points to be less or equal 
to $\varepsilon$ should be constant under the null hypothesis. The number $\mathrm{em}$ of consecutive data points to include in the set of pairs is chosen. Joint probabilities for pairs of points in the set, being less than or equal to $\varepsilon$, are calculated as the product of the individual probabilities. Under the null hypothesis of independence, a test statistic based on the (normalized) difference of correlation integrals between two equally-sized sets of pairs should be close to zero and asymptotically normally distributed with mean zero (and variance 1). Table 2 shows bootstrap $p$-values of the BDS test statistics for different combinations of em (the embedding dimension) and $\varepsilon$. As can be seen, except for a very few cases, the null hypothesis of iid stock returns is strongly rejected. For Norway, results are sensitive to the value of $\mathrm{em}$ and the level of significance chosen. The null hypothesis is rejected when $e m=3$ at the $10 \%$ level but not at the $5 \%$ level. For the UAE, the value of $\varepsilon$ matters similarly: for $\varepsilon=1$, the null hypothesis is rejected at the $5 \%$ level, for $\varepsilon=0.75$ it is rejected only at the $10 \%$ level, and for $\varepsilon=0.5$ it is not rejected at conventional levels of significance. This implies that a linear model is generally misspecified and there may be nonlinear structures in the data.

Figure 3 plots the historical time paths of the four structural shocks of the crude oil market over the period 1977-2015. To improve the readability of the plot, the values are expressed as annual averages. In fact, Figure 3 is an updated version of Figure 2 in Kilian $(2009)^{19}$, where the sample ends in December 2007. Focusing on the most recent years, we see that the four structural shocks match the recent developments in the global crude oil market, as describe in Kilian and Baumeister (2016). For example, the plunge in the oil price from 2014 onwards can be attributed to both a falling aggregate demand and a robust oil supply.

Table 3 presents estimation results of the multi-factor two-state Markov switching model for each of the eight countries. Judging by the values of sigma, State 1 is considered a "high volatility" state for Canada, Russia, the UK, and Saudi Arabia, and State 2 is a "high volatility" state for Mexico, Norway, Kuwait, and the UAE. The estimated coefficients of the high volatility state are indicated in boldface in

\footnotetext{
${ }^{19}$ Kilian's (2009) model does not include oil inventory.
} 
Table 3. The UK provides the strongest evidence for oil-supply shocks $\left(\varepsilon^{\mathrm{s}}\right)$ affecting stock returns as the estimated coefficient on this variable is negative and significant in both states. Oil-supply shocks also impact stock returns in Kuwait and the UAE in at least one state, though the coefficient is positive for Kuwait. Overall, there is evidence showing that oil-supply shocks affect the stock returns in the UK, Kuwait, and the UAE.

An unanticipated oil-demand shock $\left(\varepsilon^{\mathrm{d}}\right)$, due to a change in global aggregate demand, exerts a statistically significant impact on stock returns in at least one state for each country except Mexico and the UK. A positive flow oil-demand shock has a positive impact on stock return for all countries except State1 for Kuwait. There is strong evidence showing that flow oil-demand shocks impact stock returns in six of the eight countries studied.

The impact of an unanticipated increase in the idiosyncratic oil-market shocks ( $\left.\varepsilon^{\text {idi }}\right)$ on stock returns is significant for Norway, Russia, Kuwait, Saudi Arabia and UAE. The coefficients are positive, except for the last two countries. Judging by the magnitude of the regression coefficients, the stock returns in the three GCC Arab markets (Kuwait, Saudi Arabia and the UAE) are significantly more sensitive to idiosyncratic oil-market shocks than in the five other countries in the sample. This underscores the basic point about these Arab economies' heavy reliance on oil revenue exports as a driver of economic growth.

Finally, oil-inventory shocks $\left(\varepsilon^{\text {inv }}\right)$, which reflect the "speculative component" of the real price of oil, have a statistically significant impact on stock returns in Canada, Russia, Kuwait and the UAE. An unexpected increase in the demand for oil inventories in anticipation of, say, a future decline in oil supplies relative to demand causes an increase in stock returns in Canada, Russia, and Kuwait. However, for the UAE, a speculative shocks that increase the current real price of oil leads to a sharp decline in stock return, perhaps due to an expected downward movement in future oil prices. 
Compared to the different shocks in the crude oil market, changes in world stock returns have almost always ${ }^{20}$ highly statistically significant and positive effect on stock market returns in the oil-exporting countries, irrespective of the stock market regimes (low or high volatility). This underscores the point that movements in world stock markets matter more for predicting future stock returns in oil-exporting countries, relative to the three oil-market shocks considered in the analysis. From this point of view, there seems to be some decoupling between the stock market and the crude oil market in oil-exporting countries, albeit with vastly different orders of magnitudes. As the composition of stock markets tend to be broader in scope than that of the oil market, it is not surprising to find that after controlling for the world stock market return, the impacts of oil price shocks become less important.

Table 4 provides some inference on regimes. The expected duration in a regime is computed as $\mathrm{P}_{i j}=$ $\frac{1}{1-p_{i j}}$, where $\mathrm{P}_{i j}$ are the estimated transitional probabilities reported in Table 4. Both measures complement each other. The results imply that generally the expected duration of the low volatility state is higher than that of the high volatility state (which is indicated in boldface). This finding supports the conventional wisdom that turmoil periods have a lower duration than quieter spells (Gallo and Otranto, 2014). The diagonal elements of the transition probability matrix $P_{11}$ and $P_{22}$ respectively indicate the estimated probability of staying in State 1 and State 2 given that the market is in State 1 and State 2 in the current period. Except for Canada and Kuwait, the results imply that the probability of staying in a given state is highly persistent because the probability exceeds 0.9 . The off-diagonal elements of the transitional probability matrix $\mathrm{P}_{12}$ and $\mathrm{P}_{21}$ indicate the probability of transitioning from one state to another state. For example, for Canada and UAE the estimated probability (denoted by $\mathrm{P}_{12}$ ) implies that the market always remains in State 2. The final measure, $\mathrm{RCM}$, suggests that the lower its value is the better is the regime classification a market has within the Markov model. Hence a RCM value of 70.84 for Canada implies that regimes for Canadian data are less distinct, compared to other markets such as Russia or the UK where the distinction between the two regimes are more clear cut. Figure 4 plots the filtered probabilities

\footnotetext{
${ }^{20}$ Except for the UAE in State 1, where an unanticipated positive world stock market shock has a significantly negative effect on stock return.
} 
of the low volatility state conditioned on past and contemporaneous information in the sample. The plots are in general agreement with the values of the RCM which indicate lower values produce better fitting models. The stock market index of each market is also included in Figure 4.

There is a growing literature that examines whether oil-market shocks (in particular, oil price shock) have a symmetric or asymmetric impact on stock returns - see Alsalman and Herrera (2015) and the references therein. For example, Herrera et al. (2011) showed that asymmetry (or possibly nonlinearity) of the effect between oil price shocks and stock returns may arise due to industries' asymmetric response patterns in energy use intensity. To check for the possibility of whether the various structural oil-market shocks and world stock returns have symmetric or asymmetric effects on stock returns in oil-exporting countries, we tested for 'symmetry of coefficients' between States 1 and 2 for the Markov-switching estimates reported in Table 3. The null hypothesis is that the estimated coefficients for States 1 and 2 are symmetric, against the alternative hypothesis that they are asymmetric. The test follows a Chi-square distribution and a rejection of the null hypothesis is therefore interpreted as evidence of asymmetric (or nonlinear) effects of the various structural shocks on stock returns. Table 5 presents the results of the test of symmetry. For oil-supply shocks, evidence of asymmetry is found for Kuwait and UAE.

Flow oil-demand shocks have significant asymmetric effects on stock returns in Norway, Kuwait, and the UAE; while idiosyncratic oil-market shocks have significant asymmetric effect on stock return in Norway, Saudi Arabia, and the UAE, at the 5\% significance level with the exception of Norway at the $10 \%$ level only. Oil-inventory shocks have significant asymmetric effects in Canada and the UAE only. In contrast, changes in world stock returns have significant asymmetric effect on stock returns in five of the eight markets. Since the relationship between world stock return and domestic return is positive in both States 1 and 2 (as seen in table 3), the asymmetry is about the magnitude of the response of stock returns to changes in world return conditional on being in a particular state. For example, world stock return has a positive and significant impact on stock returns of Russia in both low and high volatility regimes, but the impact is higher in the high-volatility regime. Finally, except for Canada, the null hypothesis of 
symmetric coefficient on 'sigma' is rejected for the remaining seven countries, implying that the level of stock return volatility is significantly different between two the two regimes.

\subsection{What drives the regime transition?}

In order to get an indication of the factors contributing to the volatility of stock market returns in oilexporting countries, we make use of the estimated transition probability obtained from the Markov switching model. More specifically, we use the filtered probability associated with each country's low volatility state as the dependent variable, and regress it on two global factors: the TED interest rate spread and the global economic policy uncertainty index. By focusing on the low volatility state, we are able to examine how changes in the global factors affect volatility when stock markets are relatively calm.

Our first global measure is the TED spread, a measure of financial fear, that is defined as the difference in yields between the three-month US dollar LIBOR ("unsecured" top-rated interbank credits) and Treasury bills ("riskless" credits). ${ }^{21}$ The TED spread helps to warn investors of potential market downturns and volatility. For example, when the TED spread is increasing, it tells us that the interest rate on unsecured loans is increasing, driving up LIBOR and triggering a flight to quality towards Treasury bills. This leads to sudden liquidity dry-ups, which according to Brunnermeier and Pedersen (2009) results in a destabilizing spiral between market liquidity and funding liquidity. Boudt et al. (2017) investigated the transition between stabilizing and destabilizing funding liquidity states based on the TED spread. We follow their suggestion and use the TED spread as an explanatory variable for the transition from a tranquil (low-volatility) to a jittery (high-volatility) markets. ${ }^{22}$

Our second measure is the global economic policy uncertainty (EPU) index of Baker et al. (2015). The global EPU index has three underlying components: newspaper coverage of policy-related uncertainty, uncertainty regarding the path that the federal tax code will take in the future, and the

\footnotetext{
${ }^{21}$ Boudt et al. (2017).

${ }^{22}$ For some markets, especially Canada and Mexico, the TED spread may be less relevant. To account for this possibility, we also consider the spread between short- and long-term yields on Treasury bills (the so-called "yield curve") as a substitute of the TED spread.
} 
disagreement among economic forecasters about policy-related macroeconomic variables. In a nutshell, the global EPU index is an attempt to quantify political uncertainty and its impact on the economy. In the empirical application of their paper, Baker et al. (2015) found strong effects of policy uncertainty on stock volatility, investment and employment. The global EPU index is available in current-price GDP and PPP-adjusted GDP measures. We considered both measures in our empirical analysis. Finally, both the global EPU and the TED spread are lagged by one period to avoid any endogeneity bias with the dependent variable.

We estimate the following probit regression:

$$
P\left(d_{t}=1\right)=\Phi\left(\beta_{i} T E D_{t-1}, \gamma_{i} E P U_{t-1}\right),
$$

where $d_{t}=1$ when the state probability of stock market returns or volatility is greater than $50 \%$, and $d_{t}=0$ otherwise; it is the cumulative distribution function of the standard normal distribution. ${ }^{23}$ Tables 6-8 present probit estimates of the relationship between the global factor and filtered probabilities. Tables 6 and 7 present the results of the effects of the TED spread and global EPU separately, while Table 8 presents their joint effects. Results indicate that a jump in the previous month's TED spread lowers the probability of being in a low-volatility regime in all but one stock market (see Table 6). This result is consistent with the earlier finding of Brunnermeier and Pedersen (2009), who document that a decreased funding liquidity, or equivalently an increased TED spread, lowers market liquidity, leading to higher volatility. ${ }^{24}$ Put differently, this result suggests a role for short-term bank credit risk as a trigger for stock market volatility transition in oil-exporting countries. Our result also complements the finding in González-Hermosillo and Hesse (2009), who find that, among several global market conditions, the TED spread stays in the high-volatility state for the longest period when determining financial volatility and the likelihood of a crisis. In contrast, using the one-month lagged U.S. yield curve as an alternative explanatory factor produces less significant and mixed results. Unlike the TED spread, an increase in the yield curve slope leads to an improving economy, improving recovery rates, and decreasing credit risk

${ }^{23}$ The specification of the probit model follows the work of Angelidis et al. (2015).

${ }^{24}$ Brunnermeier and Pedersen (2009) measure volatility by VIX and allow volatility to be time-varying. 
(Fama and French, 1989). However, this explanation is far from satisfactory, because it is only an adequate description for the U.S. economy, and cannot be used to explain the significantly positive impact the yield curve has on the filtered probabilities for some countries. ${ }^{25}$

On the other hand, an increase in global EPU index ${ }^{26}$ in the previous month increases the probability of being in the low-volatility regime in the current month (in six out of eight countries) — a rather surprising result (Table 7). However, this effect is statistically significant for three countries only. A likely explanation for this result is that, by construction, the global EPU index is less sensitive to events with a strong financial and stock market connection such as the Asian financial crisis, the WorldCom fraud, and the Lehman Brothers collapse. Furthermore, the global EPU index involves no specific time horizon, unlike, say, the VIX which reflects implied volatility over a 30-day look-ahead period (see Baker et al., 2015).

Table 8 reports the joint effects of the TED spread and the global EPU index on the filtered probabilities. The results largely echo the findings suggested by Tables 6 and 7. That is, an increase in the TED spread lowers the probability of being in a low volatility regime, while an increase the global EPU index stimulates expected duration in a low volatility regime.

\section{Conclusion}

We applied a two-state Markov-switching model in order to determine the impact of shocks originating in the global oil market on the stock market performance of oil-exporting countries. For this purpose we picked eight oil-exporting countries with relatively well-functioning stock markets: Canada, Mexico, Norway, Russia, the UK, Kuwait, Saudi Arabia, and the United Arab Emirates. We used a twostep approach where the first step is the identification of structural oil shocks from an SVAR that models global oil supply and demand as in Kilian and Murphy (2014).

\footnotetext{
25 The estimates of the yield curve are not reported here to save space, but are available from the authors.

${ }^{26}$ The discussion that follows is based on the PPP-adjusted GDP measures. The results based on the current-price GDP measure are very similar to those reported in Table 7.
} 
Flow oil-demand shocks have a statistically significant impact on stock returns in Canada, Norway, Russia, Kuwait, Saudi Arabia, and the UAE. Idiosyncratic oil-market shocks affect stock returns in Norway, Russia, Kuwait, Saudi Arabia and UAE. Speculative (oil-inventory) shocks have statistically significant impacts on stock returns in Canada, Russia, Kuwait and the UAE. Oil-supply shocks matter for the UK, Kuwait, and UAE, because the shocks show statistical significance in at least one state. Mexico is the only country where stock returns are unaffected by oil shocks. This can be explained by the fact that Mexico has no large publically traded oil and gas companies. International and domestic investors need to be aware that oil shocks affect stock markets in most of the oil exporting countries studied. The signs and magnitudes of the oil shocks are country specific.

Our results support the presence of regime switching for the effects of oil shocks on stock returns in oil-exporting countries. Furthermore, a jump in the previous month's TED spread increases the probability of being in a high-volatility regime, for all but one of the countries studied. On the other hand, an increase in global economic policy uncertainty in the previous month lowers the probability of the stock market transitioning to a high-volatility regime in the current month, although compared to the TED spread the estimated coefficients are rather small.

\section{References}

Alsalman, Z. and Herrera, A.M. (2015). Oil price shocks and the U.S. stock market: Do sign and size matter? Energy Journal 36(3).

Ang, A. and Bekaert, G. (2002). Regime switches in interest rates. Journal of Business \& Economic Statistics 20, 163-182.

Angelidis, T., Degiannakis, S. and Filis, G. (2015). US stock market regimes and oil price shocks. Global Finance Journal 28, 132-146.

Apergis, N. and Miller, S.M. (2009). Do structural oil-market shocks affect stock prices? Energy Economics 31, 569-575. 
Baker, S.R., Bloom, N. and Davis, S.J. (2015). Measuring economic policy uncertainty. NBER Working Paper No. 21633. National Bureau of Economic Research, Massachusetts.

Balcilar, M., Gupta, R. and Miller, S.M. (2015). Regime switching model of US crude oil and stock market prices: 1859 to 2013. Energy Economics 49, 317-327.

Basher, S.A., Haug, A.A. and Sadorsky, P. (2012). Oil prices, exchange rates and emerging stock markets. Energy Economics 34, 227-240.

Basher, S.A., Haug, A.A. and Sadorsky, P. (2016). The impact of oil shocks on exchange rates: A Markov-switching. Energy Economics 54, 11-23.

Basher, S.A. and Sadorsky, P. (2006). Oil price risk and emerging stock markets. Global Finance Journal 17, 224-251.

Basher, S.A. and Fachin, S. (2013). The long-run relationship between savings and investment in oil-exporting developing countries: A case study of the Gulf Arab states. OPEC Energy Reviews 37, 429-446.

Basher, S.A., Nechi, S. and Zhu, H. (2014). Dependence patterns across Gulf Arab stock markets: A copula approach. Journal of Multinational Financial Management 25-26, 30-50.

Baumeister, C., and Hamilton, J.D. (2015). Structural interpretation of vector autoregressions with incomplete identification: Revisiting the role of oil supply and demand shocks. UCSD Working Paper available at http://econweb.ucsd.edu/ jhamilton/\#working.

Baumeister, C., and Kilian, L. (2016). Forty years of oil price fluctuations: Why the price of oil may still surprise us. Journal of Economic Perspectives 30, 139-160.

Beckmann, J. and Czudaj, R. (2013). Is there a homogenous causality pattern between oil prices and currencies of oil importers and exporters? Energy Economics 40, 665-678.

Bjørnland, H.C. (2009). Oil price shocks and stock market booms in an oil exporting Country. Scottish Journal of Political Economy 56, 232-254.

Boudt, K., Paulus, E.C.S. and Rosenthal, D.W.R. (2017). Funding liquidity, market liquidity and TED spread: A two-regime model. Journal of Empirical Finance 43, 143-158.

Boyer, M.M. and Filion, D. (2007). Common and fundamental factors in stock returns of Canadian oil and gas companies. Energy Economics 29, 428-453.

Brock, W.A., Dechert W.D. and Sheinkman J.A. (1987). A test of independence based on the correlation dimension. SSRI No. 8702, Department of Economics, University of Wisconsin, Madison.

Brock, W.A., Dechert, W.D., Scheinkman, J.A. and LeBaron, B. (1996). A test for independence based on the correlation dimension. Econometric Reviews 15, 197-235.

Brunnermeier, M. and Pedersen, L. (2009). Market liquidity and funding liquidity. Review of Financial Studies 22, 2201-2238.

Buetzer, S., Habib, M.M. and Stracca, L. (2016). Global exchange rate configurations: Do oil shocks matter? IMF Economic Review 64, 443-470.

Chen, S.-S. (2010). Do higher oil prices push the stock market into bear territory? Energy Economics 32, 490-495.

Demirer, R., Jategaonkar, S.P. and Khalifa, A.A.A. (2015). Oil price risk exposure and the crosssection of stock returns: The case of net exporting countries. Energy Economics 49, 132-140.

El-Sharif, I., Brown, D., Burton, B., Nixon, B. and Russell, A. (2005). Evidence on the nature and extent of the relationship between oil prices and equity values in the UK. Energy Economics 27, 819-830.

Fama, E. and French, K. (1989). Business conditions and expected returns on stocks and bonds. Journal of Financial Economics 25, 23-49. 
Ferson, W.W. and Harvey, C.R. (1994). Sources of risk and expected returns in global equity markets. Journal of Banking and Finance 18, 775-803.

Filis, G., Degiannakis, S. and Floros, C. (2011). Dynamic correlation between stock market and oil prices: The case of oil-importing and oil-exporting countries. International Review of Financial Analysis 20, 152-164.

Gallo, G.M. and Otranto, E. (2014). Forecasting realized volatility with changes of regimes. Available at SSRN: https://ssrn.com/abstract=2390780

González-Hermosillo, B. and Hesse, H. (2009). Global market conditions and systematic risks. IMF Working Paper No. 230. International Monetary Fund, Washington DC

Guesmi, K. and Fattoum, S. (2014). Return and volatility transmission between oil prices and oil-exporting and oil-importing countries. Economic Modelling 38, 305-310.

Hamilton, J.D. (1990). Analysis of time series subject to changes in regime. Journal of Econometrics 45, 39-70.

Hamilton, J.D. (1994). Time series analysis. Princeton University Press, Princeton, NJ.

Hamilton, J.D. (2003). What is an oil shock? Journal of Econometrics 113, 363-398.

Hamilton, J.D. (2011). Nonlinearities and the macroeconomic effects of oil prices. Macroeconomic Dynamics 15, 364-378.

Hamilton, J.D. (2016). Macroeconomic regimes and regime shifts. NBER Working Paper No. 21863

Hammoudeh, S. and Aleisa, E. (2004). Dynamic relationships among GCC stock markets and NYMEX oil futures. Contemporary Economic Policy 22, 250-269.

Herrera, A.M., Lagalo, L.G. and Wada, T. (2011). Oil price shocks and industrial production: Is the relationship linear? Macroeconomic Dynamics 15, 472-497.

Huang, B.-N., Hwang, M.J. and Peng, H.-P. (2005). The asymmetry of the impact of oil price shocks on economic activities: An application of the multivariate threshold model. Energy Economics 27, 455-476.

Inoue, A. and Kilian, L. (2013). Inference on impulse response functions in structural VAR models. Journal of Econometrics 177, 1-13.

Jones, C. and Kaul, G. (1996). Oil and the stock markets. Journal of Finance 51, 463-91.

Jung, H. and Park, C. (2011). Stock market reaction to oil price shocks: A comparison between an oil-exporting economy and an oil-importing economy. Journal of Economic Theory and Econometrics 22, 1-29.

Kang, W. and Ratti, R. (2013). Oil shocks, policy uncertainty and stock market return. Journal of International Financial Markets, Institutions and Money 26, 305-318.

Kang, W., Ratti, R., and Yoon, K.H. (2015). Time-varying effect of oil market shocks on the stock market. Journal of Banking and Finance 61, S150-S163.

Kilian, L. (2009). Not all oil price shocks are alike: disentangling demand and supply shocks in the crude oil market. American Economic Review 99, 1053-1069.

Kilian, L. and Lee, T.K. (2014). Quantifying the speculative component in the real price of oil: The role of global oil inventories. Journal of International Money and Finance 42, 71-87.

Kilian, L. and Murphy, D.P. (2012). Why agnostic sign restrictions are not enough: Understanding the dynamics of oil market VAR models. Journal of the European Economic Association 10, 1166-1188.

Kilian, L. and Murphy, D.P. (2014). The role of inventories and speculative trading in the global market for crude oil. Journal of Applied Econometrics 29, 454-478. 
Kilian, L. and Park, C. (2009). The impact of oil price shocks on the U.S. stock market. International Economic Review 50, 1267-1287.

Kilian, L. and Vigfusson, R.J. (2011). Nonlinearities in the oil price-output relationship. Macroeconomic Dynamics 15, 337-363.

Mohanty, S.K., Nandha, M., Turkistani, A.Q. and Alaitani, M.Y. (2011). Oil price movements and stock market returns: Evidence from Gulf Cooperation Council (GCC) countries. Global Finance Journal 22, 42-55.

Mork, K.A. (1989). Oil and the macroeconomy. When prices go up and down: An extension of Hamilton's results. Journal of Political Economy 97, 740-744.

Murphy, K.M. and Topel, R.H. (1985). Estimation and inference in two-step econometric models estimation. Journal of Business and Economic Statistics 3, 88-97.

Pagan, A.R. (1984). Econometric issues in the analysis of regressions with generated regressors. International Economic Review 25, 221-247.

Park, J. and Ratti, R.A. (2008). Oil price shocks and stock markets in the US and 13 European countries. Energy Economics 30, 2587-2608.

Ramos, S.B. and Veiga, H. (2013). Oil price asymmetric effects: Answering the puzzle in international stock markets. Energy Economics 38, 136-145.

Sadorsky, P. (1999). Oil price shocks and stock market activity. Energy Economics 21, 449-69.

Sadorsky, P. (2001). Risk factors in stock returns of Canadian oil and gas companies. Energy Economics 23, 17-28.

Sim, N. and Zhou, H. (2015). Oil prices, US stock return, and the dependence between their quantiles. Journal of Banking and Finance 55, 1-8.

Sims, C.A., Stock, J.H., and Watson, M.W. (1990). Inference in linear time series models with some unit roots. Econometrica 58, 113-144.

Wang, Y., Wu, C., and Yang, L. (2013). Oil price shocks and stock market activities: Evidence from oil-importing and oil-exporting countries. Journal of Comparative Economics 41, $1220-1239$.

Wooldridge, J.M. (2010). Econometric analysis of cross section and panel data. Second edition, MIT Press, Cambridge, Mass. 
Table 1. Summary statistics

\begin{tabular}{|c|c|c|c|c|c|c|c|}
\hline Variable & Obs & Mean & Std. Dev. & Min & Max & $\mathrm{PP}$ & DF-GLS \\
\hline$\varepsilon^{\mathrm{s}}$ & 475 & 0.000 & 0.893 & -3.310 & 2.321 & $-21.711^{\mathrm{a}}$ & $-13.305^{\mathrm{a}}$ \\
\hline$\varepsilon^{\mathrm{d}}$ & 475 & 0.000 & 0.893 & -4.646 & 2.916 & $-21.664^{\mathrm{a}}$ & $-3.396^{\mathrm{a}}$ \\
\hline$\varepsilon^{\mathrm{idi}}$ & 475 & 0.000 & 0.893 & -3.140 & 4.076 & $-21.704^{\mathrm{a}}$ & $-12.703^{a}$ \\
\hline$\varepsilon^{\text {inv }}$ & 475 & 0.000 & 0.893 & -3.811 & 3.132 & $-22.038^{\mathrm{a}}$ & -1.993 \\
\hline can_r & 475 & 0.362 & 5.828 & -31.449 & 19.264 & $-20.565^{\mathrm{a}}$ & $-4.830^{\mathrm{a}}$ \\
\hline mex_r & 332 & 1.098 & 8.881 & -42.332 & 24.947 & $-16.667^{a}$ & -0.673 \\
\hline nor_r & 475 & 0.370 & 7.963 & -40.643 & 19.434 & $-19.563^{\mathrm{a}}$ & $-2.208^{b}$ \\
\hline rus_r & 248 & 0.566 & 15.476 & -93.458 & 47.284 & $-13.402^{\mathrm{a}}$ & $-2.338^{b}$ \\
\hline uk_r & 475 & 0.472 & 5.496 & -24.748 & 20.077 & $-21.028^{\mathrm{a}}$ & $-4.672^{\mathrm{a}}$ \\
\hline kuw_r & 123 & -0.073 & 6.594 & -21.333 & 19.624 & $-8.475^{a}$ & $-3.457^{a}$ \\
\hline sau_r & 123 & -0.158 & 8.599 & -29.357 & 18.878 & $-9.944^{\mathrm{a}}$ & $-2.751^{\mathrm{a}}$ \\
\hline uae_r & 123 & -0.180 & 9.980 & -33.066 & 23.385 & $-9.937^{a}$ & $-2.709^{a}$ \\
\hline world_r & 475 & 0.415 & 4.256 & -21.046 & 10.710 & $-20.170^{\mathrm{a}}$ & $-9.966^{\mathrm{a}}$ \\
\hline
\end{tabular}

Monthly data are from February 1976 to December 2015. PP is the Phillips-Perron Z(t) unit root test. DF-GLS is the Dickey-Fuller GLS unit root test with lag length selected using the Schwarz Bayesian Information Criterion (SBIC). A rejection of the null hypothesis by both tests suggests that the variable in question is stationary (contains no unit root). The variables ending with_r denote excess stock market returns. Significance at the $1 \%\left({ }^{\mathrm{a}}\right)$ and $5 \%\left({ }^{\mathrm{b}}\right)$ levels is reported for unit root tests. 
Table 2. BDS tests for nonlinearity in excess stock returns

\begin{tabular}{|c|c|c|c|}
\hline Country/em & $\varepsilon(0.5)$ & $\varepsilon(0.75)$ & $\varepsilon(1.0)$ \\
\hline \multicolumn{4}{|l|}{ CAN } \\
\hline 2.000 & 0.001 & 0.002 & 0.001 \\
\hline 3.000 & $<0.001$ & $<0.001$ & $<0.001$ \\
\hline \multicolumn{4}{|l|}{ MEX } \\
\hline 2.000 & $<0.001$ & $<0.001$ & $<0.001$ \\
\hline 3.000 & $<0.001$ & $<0.001$ & $<0.001$ \\
\hline \multicolumn{4}{|l|}{ NOR } \\
\hline 2.000 & 0.198 & 0.327 & 0.184 \\
\hline 3.000 & 0.075 & 0.099 & 0.067 \\
\hline \multicolumn{4}{|l|}{ RUS } \\
\hline 2.000 & $<0.001$ & $<0.001$ & $<0.001$ \\
\hline 3.000 & $<0.001$ & $<0.001$ & $<0.001$ \\
\hline \multicolumn{4}{|l|}{ UK } \\
\hline 2.000 & $<0.001$ & $<0.001$ & $<0.001$ \\
\hline 3.000 & $<0.001$ & $<0.001$ & $<0.001$ \\
\hline \multicolumn{4}{|l|}{ KUW } \\
\hline 2.000 & 0.024 & 0.026 & 0.011 \\
\hline 3.000 & 0.025 & 0.009 & 0.002 \\
\hline \multicolumn{4}{|l|}{ SAU } \\
\hline 2.000 & $<0.001$ & $<0.001$ & $<0.001$ \\
\hline 3.000 & $<0.001$ & $<0.001$ & $<0.001$ \\
\hline \multicolumn{4}{|l|}{ UAE } \\
\hline 2.000 & 0.124 & 0.094 & 0.023 \\
\hline 3.000 & 0.204 & 0.091 & 0.018 \\
\hline
\end{tabular}

Bootstrap $p$-values are shown for the BDS test computed using 5000 bootstraps. The BDS test is

computed on the residuals from an AR(1) model of monthly excess stock returns. The embedding dimension is denoted $e m$ and the distance is $\varepsilon$. 
Table 3. Markov-switching estimates with oil shocks

\begin{tabular}{|c|c|c|c|c|c|c|c|c|}
\hline & $\begin{array}{c}(1) \\
\text { CAN }\end{array}$ & $\begin{array}{c}(2) \\
\mathrm{MEX}\end{array}$ & $\begin{array}{c}(3) \\
\text { NOR }\end{array}$ & $\begin{array}{c}(4) \\
\text { RUS }\end{array}$ & $\begin{array}{l}(5) \\
\text { UK } \\
\end{array}$ & $\begin{array}{c}(6) \\
\text { KUW }\end{array}$ & $\begin{array}{c}(7) \\
\text { SAU }\end{array}$ & $\begin{array}{c}(8) \\
\text { UAE }\end{array}$ \\
\hline \multicolumn{9}{|l|}{ STATE 1} \\
\hline \multirow[t]{2}{*}{$\varepsilon^{\mathrm{s}}$} & -0.303 & -0.0432 & -0.549 & 2.238 & $-0.901^{b}$ & $3.759^{a}$ & -3.560 & $-18.20^{\mathrm{a}}$ \\
\hline & $(-0.47)$ & $(-0.10)$ & $(-1.55)$ & $(0.46)$ & $(-2.45)$ & $(3.48)$ & $(-0.95)$ & $(-130.45)$ \\
\hline \multirow[t]{2}{*}{$\varepsilon^{\mathrm{d}}$} & $1.189^{c}$ & 0.448 & $0.558^{\mathrm{b}}$ & 0.587 & 0.0521 & $-2.359^{a}$ & 3.793 & $3.575^{\mathrm{a}}$ \\
\hline & (1.94) & $(1.42)$ & $(2.15)$ & $(0.14)$ & (0.12) & $(-7.12)$ & (1.47) & (114.30) \\
\hline \multirow[t]{2}{*}{$\varepsilon^{\text {idi }}$} & 0.551 & -0.00757 & $0.846^{\mathrm{a}}$ & -2.502 & 0.559 & $2.321^{\mathrm{b}}$ & $-7.852^{a}$ & $-10.40^{\mathrm{a}}$ \\
\hline & (1.34) & $(-0.03)$ & $(2.76)$ & $(-0.81)$ & (1.21) & $(2.13)$ & $(-3.41)$ & $(-145.13)$ \\
\hline \multirow[t]{2}{*}{$\varepsilon^{\text {inv }}$} & -0.684 & 0.0129 & 0.125 & -2.866 & 0.344 & $1.875^{\mathrm{a}}$ & -1.241 & $-11.74^{a}$ \\
\hline & $(-1.58)$ & $(0.03)$ & $(0.30)$ & $(-0.74)$ & (1.05) & $(2.61)$ & $(-0.39)$ & $(-127.42)$ \\
\hline \multirow[t]{2}{*}{ World } & $1.385^{\mathrm{a}}$ & $1.207^{\mathrm{a}}$ & $1.356^{\mathrm{a}}$ & $3.278^{\mathrm{a}}$ & $1.128^{\mathrm{a}}$ & $0.943^{\mathrm{a}}$ & -0.388 & $-0.778^{a}$ \\
\hline & (8.93) & $(15.86)$ & $(15.26)$ & (3.64) & (15.88) & (14.18) & $(-0.50)$ & $(-54.55)$ \\
\hline \multirow[t]{2}{*}{ Constant } & $-1.513^{b}$ & 0.400 & 0.445 & -1.069 & 0.122 & -0.196 & $-6.781^{a}$ & $-13.73^{a}$ \\
\hline & $(-2.02)$ & $(0.82)$ & $(1.37)$ & $(-0.40)$ & (0.39) & $(-0.42)$ & $(-3.74)$ & $(-174.91)$ \\
\hline \multirow[t]{2}{*}{ Sigma } & $3.407^{a}$ & $3.857^{\mathrm{a}}$ & $3.581^{\mathrm{a}}$ & $19.765^{a}$ & $4.480^{\mathrm{a}}$ & $1.258^{\mathrm{a}}$ & $9.104^{a}$ & $0.151^{\mathrm{a}}$ \\
\hline & $(5.982)$ & $(7.340)$ & $(15.691)$ & (11.822) & (18.819) & $(2.599)$ & $(10.270)$ & $(4.020)$ \\
\hline \multicolumn{9}{|l|}{ STATE 2} \\
\hline \multirow[t]{2}{*}{$\varepsilon^{\mathrm{s}}$} & 0.106 & -0.536 & 0.268 & 0.480 & $-0.339^{c}$ & -1.302 & -0.0999 & -0.748 \\
\hline & $(0.31)$ & $(-0.46)$ & $(0.66)$ & $(0.64)$ & $(-1.76)$ & $(-1.34)$ & $(-0.13)$ & $(-0.68)$ \\
\hline \multirow[t]{2}{*}{$\varepsilon^{\mathrm{d}}$} & 0.445 & 0.135 & $2.170^{\mathrm{a}}$ & $1.831^{\mathrm{a}}$ & 0.0624 & $1.235^{b}$ & $0.921^{\mathrm{c}}$ & $1.608^{a}$ \\
\hline & $(1.42)$ & $(\mathbf{0 . 1 0})$ & $(4.60)$ & $(3.29)$ & $(0.54)$ & (2.13) & $(1.71)$ & (2.72) \\
\hline \multirow[t]{2}{*}{$\varepsilon^{\text {idi }}$} & 0.219 & 0.0534 & -0.170 & $1.102^{\mathrm{b}}$ & 0.0159 & 0.360 & 0.504 & 0.424 \\
\hline & (1.06) & $(0.04)$ & $(-0.40)$ & $(2.25)$ & $(0.12)$ & $(0.63)$ & $(1.02)$ & $(0.79)$ \\
\hline \multirow[t]{2}{*}{$\varepsilon^{\text {inv }}$} & $0.576^{\mathrm{b}}$ & -0.0572 & 0.283 & $1.409^{\mathrm{c}}$ & -0.105 & 0.484 & 1.030 & $2.482^{b}$ \\
\hline & $(2.46)$ & $(-0.06)$ & $(0.56)$ & (1.94) & $(-0.51)$ & $(0.48)$ & $(1.26)$ & (2.15) \\
\hline \multirow[t]{2}{*}{ World } & $0.818^{\mathrm{a}}$ & $1.072^{a}$ & $1.170^{a}$ & $1.410^{\mathrm{a}}$ & $0.937^{a}$ & $0.493^{a}$ & $0.620^{\mathrm{a}}$ & $0.975^{a}$ \\
\hline & $(9.35)$ & (4.16) & (10.09) & (11.70) & $(28.44)$ & (3.67) & $(4.32)$ & $(8.23)$ \\
\hline \multirow[t]{2}{*}{ Constant } & $0.655^{\mathrm{c}}$ & 1.025 & -0.571 & 0.258 & -0.0240 & -0.294 & 0.536 & -0.151 \\
\hline & $(1.78)$ & (1.09) & $(-1.22)$ & $(0.47)$ & $(-0.19)$ & $(-0.47)$ & $(0.90)$ & $(-0.23)$ \\
\hline \multirow{2}{*}{ Sigma } & $3.129^{\mathrm{a}}$ & $9.916^{a}$ & $6.860^{a}$ & $7.007^{\mathrm{a}}$ & $2.082^{\mathrm{a}}$ & $5.702^{a}$ & $4.944^{\mathrm{a}}$ & $6.997^{a}$ \\
\hline & $(12.546)$ & $(5.579)$ & $(19.926)$ & $(20.887)$ & $(20.960)$ & $(8.971)$ & (12.319) & (15.159) \\
\hline Log likelihood & -1270.3 & -1066.9 & -1465.8 & -915.6 & -1185.7 & -375.6 & -400.4 & -408.4 \\
\hline $\mathrm{N}$ & 475 & 332 & 475 & 248 & 475 & 123 & 123 & 123 \\
\hline SBIC & 5.556 & 6.707 & 6.379 & 7.739 & 5.200 & 6.733 & 7.137 & 7.267 \\
\hline
\end{tabular}


Table 4. Summary statistics for Markov-switching estimates with oil shocks

\begin{tabular}{lcccccccc}
\hline & CAN & MEX & NOR & RUS & UK & KUW & SAU & UAE \\
\hline dur 1 & $\mathbf{1 . 0 0 0}$ & 243.567 & 40.780 & $\mathbf{1 7 3 . 5 1 0}$ & $\mathbf{3 9 0 . 4 9 4}$ & 1.000 & $\mathbf{2 7 . 2 6 5}$ & 1.000 \\
dur 2 & 1.882 & $\mathbf{2 1 8 . 7 5 0}$ & $\mathbf{4 3 . 9 8 0}$ & 273.245 & 447.928 & $\mathbf{3 . 3 9 2}$ & 102.195 & $\mathbf{1 2 . 5 6 7}$ \\
$\mathrm{P}_{11}$ & 0.000 & 0.996 & 0.975 & 0.994 & 0.997 & 0.000 & 0.963 & 0.000 \\
$\mathrm{P}_{12}$ & 1.000 & 0.004 & 0.025 & 0.006 & 0.003 & 0.999 & 0.037 & 1.000 \\
$\mathrm{P}_{21}$ & 0.531 & 0.005 & 0.023 & 0.004 & 0.002 & 0.295 & 0.010 & 0.080 \\
$\mathrm{P}_{22}$ & 0.469 & 0.995 & 0.977 & 0.996 & 0.998 & 0.705 & 0.990 & 0.920 \\
$\mathrm{RCM}$ & 70.840 & 13.216 & 37.440 & 8.731 & 10.607 & 37.819 & 10.040 & 2.402 \\
\hline \multicolumn{2}{l}{ Values in boldface indicate a high volatility regime. dur 1 and dur 2 refer to expected duration (in months) in a regime, and is }
\end{tabular}

computed as $\mathrm{P}_{\mathrm{ij}}=1 /\left(1-p_{i j}\right)$, where $p_{i j}$ are the estimated transitional probabilities. RCM is the Regime Classification Measure of Ang and Bekaert (2002).

Table 5. Tests for symmetry between states for Markov-switching estimates

\begin{tabular}{lcccccccc}
\hline & CAN & MEX & NOR & RUS & UK & KUW & SAU & UAE \\
\hline$\varepsilon^{\mathrm{s}}$ & 0.208 & 0.171 & 2.570 & 0.127 & 1.784 & 12.457 & 0.842 & 245.967 \\
& $(0.649)$ & $(0.679)$ & $(0.109)$ & $(0.722)$ & $(0.182)$ & $(0.000)$ & $(0.359)$ & $(0.000)$ \\
$\varepsilon^{\mathrm{d}}$ & 0.754 & 0.048 & 8.823 & 0.093 & 0.001 & 25.739 & 1.192 & 11.010 \\
& $(0.385)$ & $(0.827)$ & $(0.003)$ & $(0.760)$ & $(0.981)$ & $(0.000)$ & $(0.275)$ & $(0.001)$ \\
\multirow{4}{*}{$\varepsilon^{\text {idi }}$} & 0.508 & 0.003 & 3.479 & 1.307 & 1.236 & 2.521 & 12.682 & 394.70 \\
& $(0.476)$ & $(0.960)$ & $(0.062)$ & $(0.253)$ & $(0.266)$ & $(0.112)$ & $(0.000)$ & $(0.000)$ \\
$\varepsilon^{\text {inv }}$ & 5.691 & 0.004 & 0.053 & 1.175 & 1.338 & 1.070 & 0.505 & 150.172 \\
& $(0.017)$ & $(0.949)$ & $(0.818)$ & $(0.278)$ & $(0.247)$ & $(0.301)$ & $(0.477)$ & $(0.000)$ \\
\multirow{3}{*}{ world } & 6.175 & 0.249 & 1.426 & 4.169 & 6.035 & 8.758 & 1.635 & 214.77 \\
& $(0.013)$ & $(0.618)$ & $(0.232)$ & $(0.041)$ & $(0.014)$ & $(0.003)$ & $(0.201)$ & $(0.000)$ \\
sigma & 0.142 & 89.190 & 80.205 & 115.177 & 155.332 & 17.292 & 22.508 & 222.104 \\
& $(0.706)$ & $(0.000)$ & $(0.000)$ & $(0.000)$ & $(0.000)$ & $(0.000)$ & $(0.000)$ & $(0.000)$ \\
\hline
\end{tabular}

The table reports chi-squared values and associated p-values (in parentheses) of testing symmetry between each state. A $p$ -

value higher than 0.05 indicates the rejection of the null hypothesis of symmetry at the $5 \%$ level of significance. 
Table 6. Probit model estimates for the impact of TED spread on filtered probabilities (low volatility state)

\begin{tabular}{|c|c|c|c|c|c|c|c|c|}
\hline & (1) & (2) & (3) & (4) & (5) & (6) & (7) & (8) \\
\hline \multirow{3}{*}{$\mathrm{TED}_{\mathrm{t}-1}$} & $\mathrm{CAN}$ & MEX & NOR & RUS & UK & KUW & SAU & UAE \\
\hline & -0.119 & $-0.797^{\mathrm{a}}$ & $-1.444^{\mathrm{a}}$ & $-0.818^{\mathrm{a}}$ & $-0.982^{\mathrm{a}}$ & -0.0155 & $-3.091^{\mathrm{a}}$ & 0.358 \\
\hline & $(-0.70)$ & $(-3.04)$ & $(-6.26)$ & $(-2.70)$ & $(-4.27)$ & $(-0.07)$ & $(-5.07)$ & $(1.34)$ \\
\hline \multirow[t]{2}{*}{ Constant } & $1.019^{a}$ & $0.468^{a}$ & $1.064^{\mathrm{a}}$ & $0.928^{a}$ & $1.158^{\mathrm{a}}$ & $-0.712^{\mathrm{a}}$ & $2.128^{\mathrm{a}}$ & $-1.601^{\mathrm{a}}$ \\
\hline & $(7.83)$ & $(3.11)$ & $(7.58)$ & $(5.64)$ & $(7.57)$ & $(-4.18)$ & $(8.21)$ & $(-6.71)$ \\
\hline Log likelihood & -162.6 & -218.2 & -208.3 & -146.0 & -197.1 & -67.18 & -43.54 & -33.82 \\
\hline $\mathrm{N}$ & 355 & 332 & 355 & 248 & 355 & 123 & 123 & 123 \\
\hline SBIC & 337.0 & 448.1 & 428.4 & 303.1 & 406.0 & 144.0 & 96.71 & 77.26 \\
\hline
\end{tabular}

$t$ statistics are given in parentheses. The $t$ statistics are calculated using robust standard errors. ${ }^{\mathrm{c}} p<0.10,{ }^{\mathrm{b}} p<0.05,{ }^{\mathrm{a}} p<0.01$.

Table 7. Probit model estimates for the impact of global economic policy uncertainty (EPU) on filtered probabilities (low volatility state)

\begin{tabular}{|c|c|c|c|c|c|c|c|}
\hline & (1) & (2) & (3) & (4) & (5) & (6) & (7) \\
\hline \multirow{3}{*}{$\log \operatorname{EPU}_{\mathrm{t}-1}$} & CAN & MEX & NOR & RUS & KUW & SAU & UAE \\
\hline & -0.165 & $1.422^{\mathrm{a}}$ & 0.212 & $1.681^{\mathrm{a}}$ & 0.0136 & $1.799^{\mathrm{a}}$ & -0.660 \\
\hline & $(-0.57)$ & $(5.22)$ & $(0.85)$ & $(5.62)$ & $(0.04)$ & $(3.91)$ & $(-1.21)$ \\
\hline \multirow[t]{2}{*}{ Constant } & 1.686 & $-5.691^{\mathrm{a}}$ & -0.554 & $-6.805^{\mathrm{a}}$ & -0.783 & $-7.689^{a}$ & 1.632 \\
\hline & $(1.28)$ & $(-4.63)$ & $(-0.49)$ & $(-5.08)$ & $(-0.48)$ & $(-3.70)$ & $(0.66)$ \\
\hline Log likelihood & -103.2 & -113.8 & -142.7 & -108.2 & -67.18 & -61.21 & -33.63 \\
\hline $\mathrm{N}$ & 223 & 223 & 223 & 223 & 123 & 123 & 123 \\
\hline SBIC & 217.2 & 238.4 & 296.3 & 227.1 & 144.0 & 132.1 & 76.89 \\
\hline
\end{tabular}

See Table 6. 
Table 8. Probit model estimates for the impact of TED spread and global policy uncertainty (CUR) on filtered probabilities (low volatility state)

\begin{tabular}{|c|c|c|c|c|c|c|c|}
\hline & (1) & (2) & (3) & (4) & (5) & (6) & (7) \\
\hline & CAN & MEX & NOR & RUS & KUW & SAU & UAE \\
\hline $\mathrm{TED}_{\mathrm{t}-1}$ & $\begin{array}{l}-0.264 \\
(-122)\end{array}$ & $\begin{array}{c}-0.703^{a} \\
(-332\end{array}$ & $\begin{array}{r}-1.936^{a} \\
(-478)\end{array}$ & $\begin{array}{c}-1.099^{a} \\
(-448)\end{array}$ & -0.016 & $-5.735^{\mathrm{a}}$ & 0.452 \\
\hline $\log _{E P U_{t} 1}$ & $\begin{array}{l}-0.155 \\
(-0.54)\end{array}$ & $\begin{array}{l}1.480^{\mathrm{a}} \\
(5.38)\end{array}$ & $\begin{array}{l}0.046 \\
(0.19)\end{array}$ & $\begin{array}{l}1.905^{\mathrm{a}} \\
(5.91)\end{array}$ & $\begin{array}{l}0.014 \\
(0.04)\end{array}$ & $\begin{array}{l}5.690^{\mathrm{a}} \\
(3.93)\end{array}$ & $\begin{array}{l}-0.853 \\
(-1.89)\end{array}$ \\
\hline Constant & $\begin{array}{l}1.770 \\
(1.35)\end{array}$ & $\begin{array}{l}-5.570^{\mathrm{a}} \\
(-4.51)\end{array}$ & $\begin{array}{l}1.186 \\
(1.03)\end{array}$ & $\begin{array}{l}-7.167^{\mathrm{a}} \\
(-4.99)\end{array}$ & $\begin{array}{l}-0.780 \\
(-0.48)\end{array}$ & $\begin{array}{c}-21.414^{\mathrm{a}} \\
(-3.85)\end{array}$ & $\begin{array}{l}2.247 \\
(1.08)\end{array}$ \\
\hline Log likelihood & -102.5 & -109.1 & -114.4 & -97.3 & -67.1 & -18.6 & -32.4 \\
\hline $\mathrm{N}$ & 223 & 223 & 223 & 223 & 123 & 123 & 123 \\
\hline SBIC & 221.2 & 234.5 & 245.1 & 210.9 & 148.7 & 51.7 & 79.3 \\
\hline
\end{tabular}

See Table 6. 
Figure 1. Oil rents (\% of GDP), annual figures

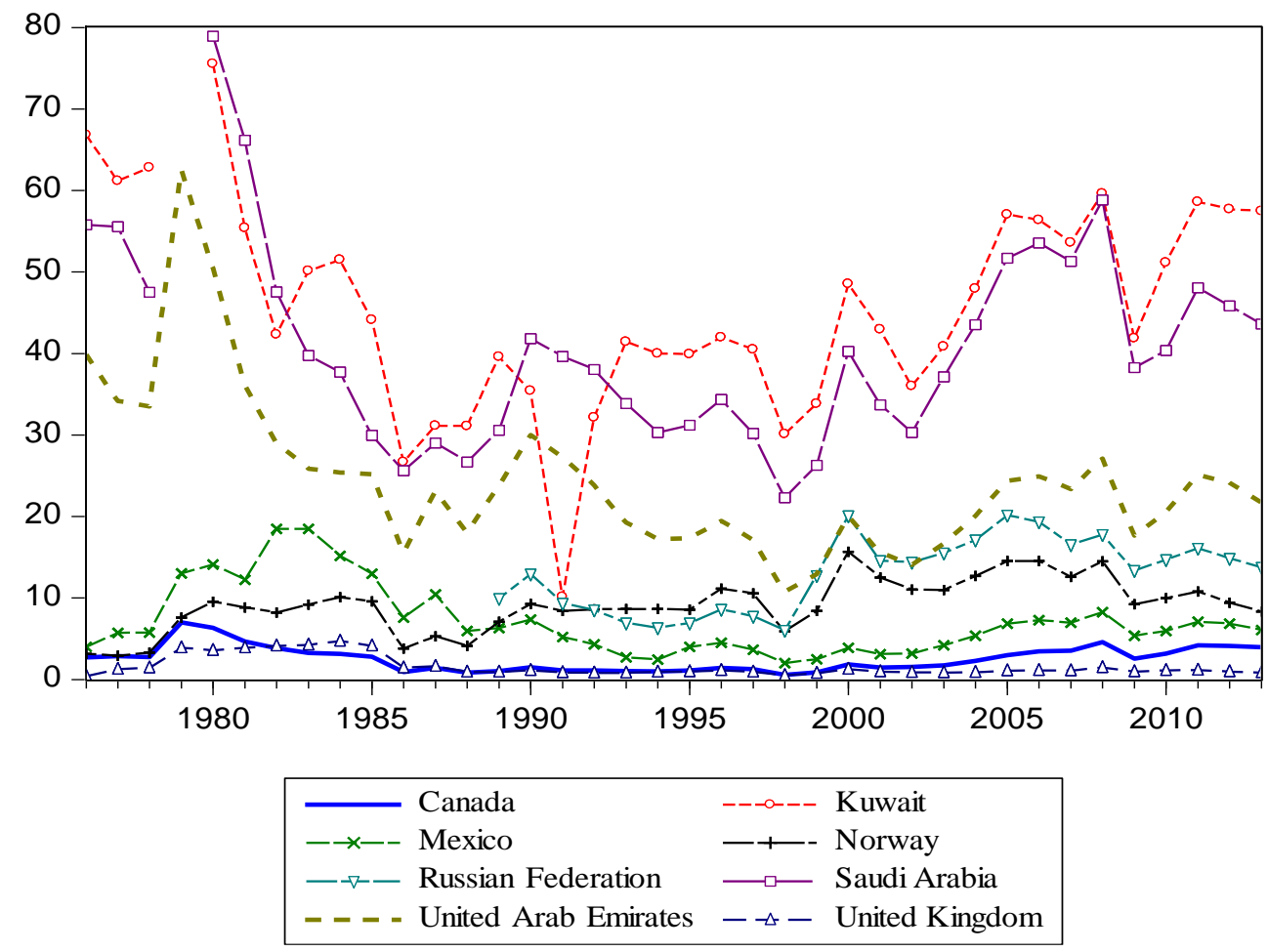

Oil rents are the difference between the value of crude oil production at world prices and total costs of production. The annual data for the period from 1976 to 2013 (the latest year available) are from the World Development Indicators web site at http://wdi.worldbank.org/table/3.15.

Data for Russia are not available before 1989. 
Figure 2. Time series plots of the stock indices

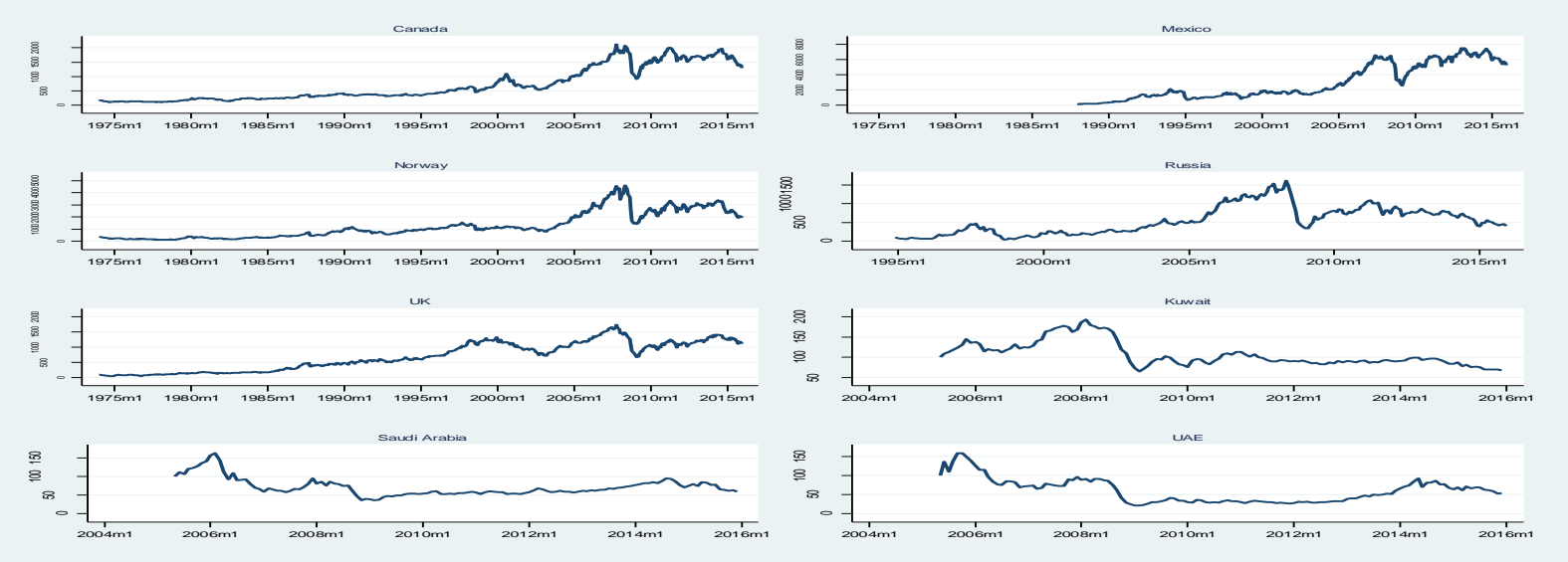

Figure 3. Time series plots of oil shocks

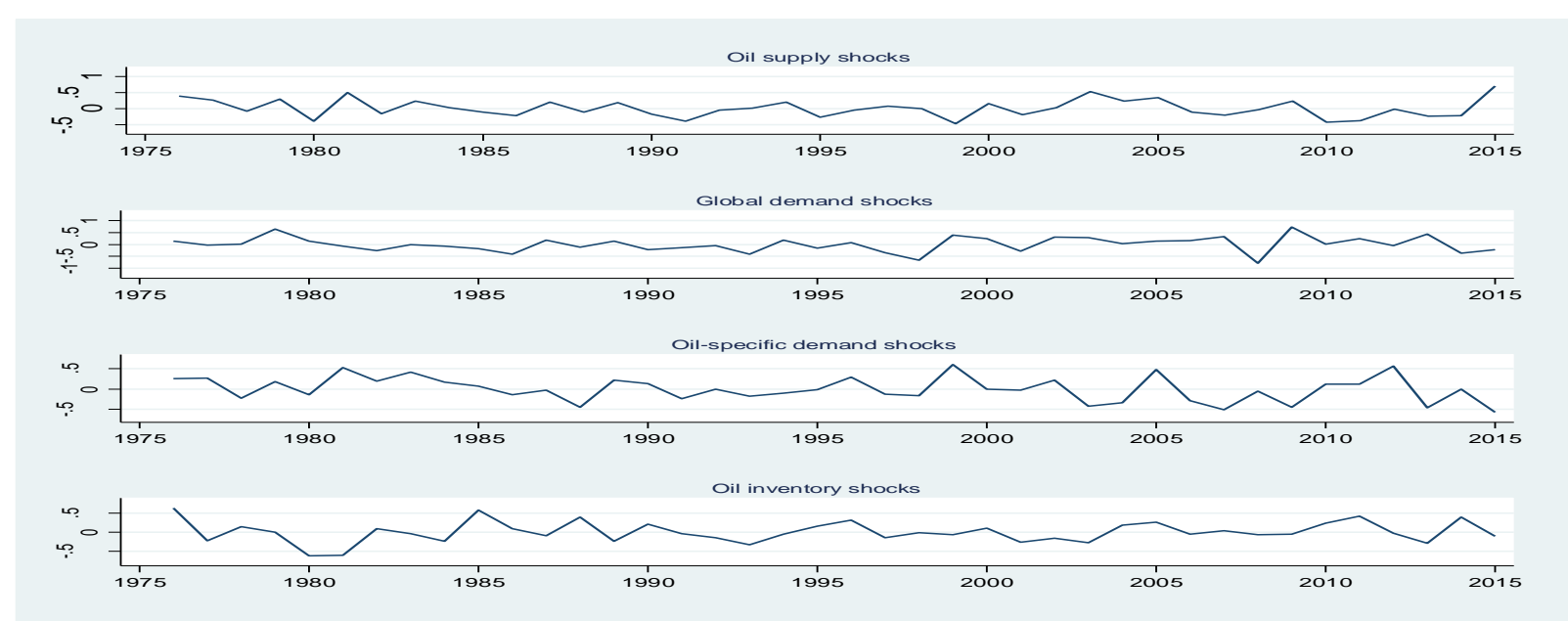

The graph shows structural shocks to the global market for crude oil as discussed in Kilian and Murphy (2014). For improved visibility, the shocks are presented at the annual frequency by averaging the monthly structural innovation for each year. 
Figure 4. Filter probabilities for low volatility state from symmetrical Markov Switching model
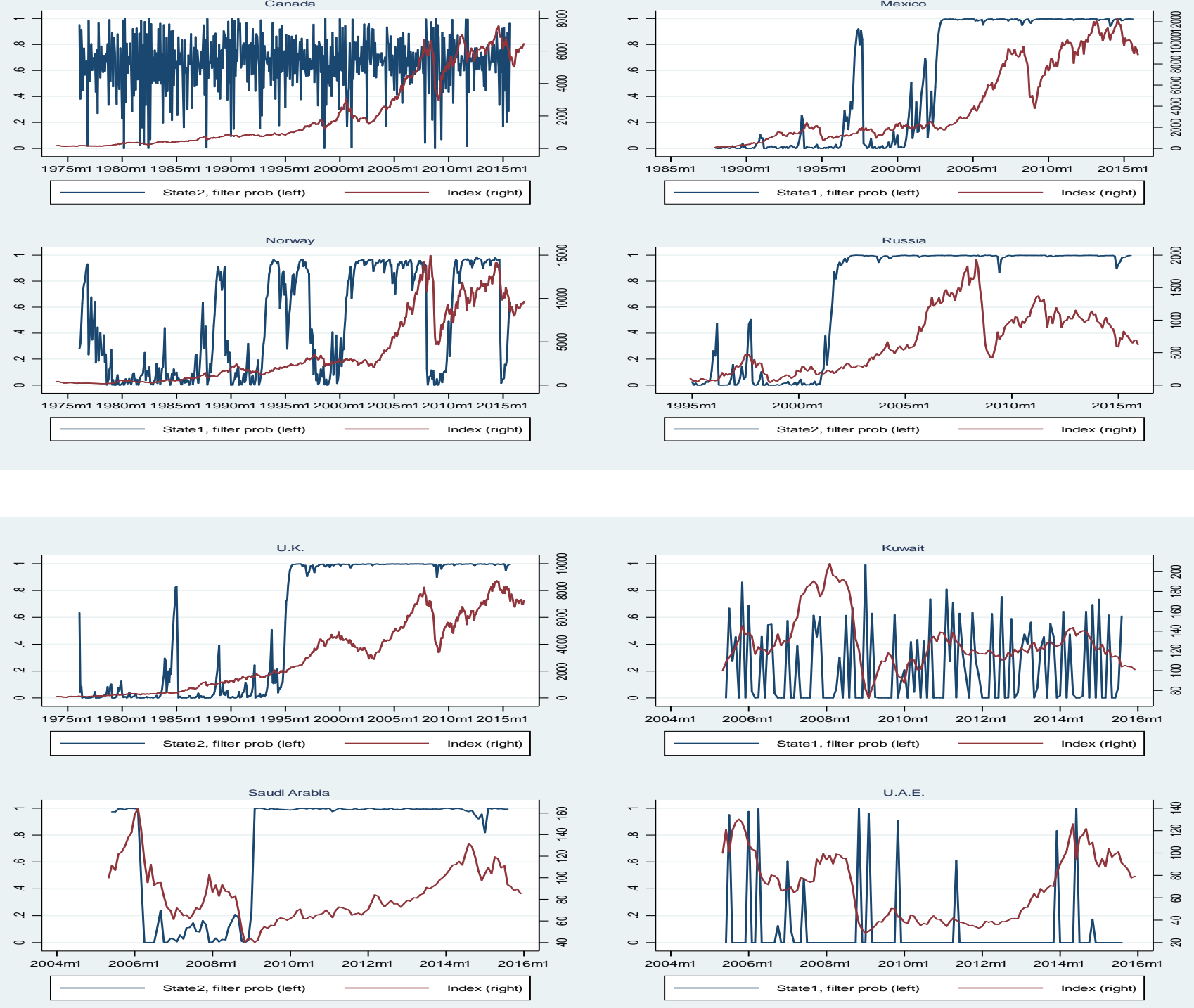